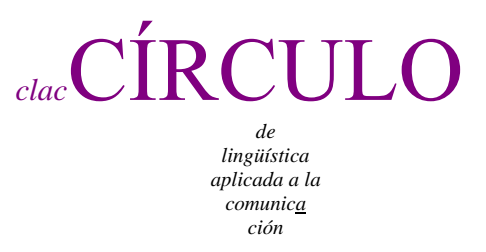

$66 / 2016$

\title{
APROXIMACIÓN AL CLÍTICO 的 DE EN CHINO
}

\author{
Zhi Chen 陈芷 \\ Universidad de Estudios Internacionales de Shanghai \\ liria chenzhi en gmail.com
}

Resumen

Debido a las características intrínsecas de la lengua china, los clíticos juegan un papel imprescindible en la estructura sintáctica del idioma. Sin ellos, las oraciones no llegan a construirse, ya que son estos, entre otros recursos, los que cargan las informaciones gramaticales; es más, cada clítico en chino ocupa un hueco en la gramática, por lo que es difícil remplazarlos sin cambiar el sentido de la oración.

De todos los clíticos, la palabra «的» es la que se presenta con mayor frecuencia. Esta palabra, como muchas otras "palabras vacías", desempeña diversas funciones gramaticales, por lo que constituye un punto de investigación muy interesante en la gramática china. Desde los años 20 del siglo pasado, generaciones de eruditos se han dedicado a su estudio, entre otros, figuran Li Jinxi (黎锦熙), Gao Mingkai（高名凯),

Chen, Zhi 陈芷. 2016.

Aproximación al clítico 的 de en chino.

Círculo de Lingüística Aplicada a la Comunicación 66, 23-50.

http://www.ucm.es/info/circulo/no66/chenzhi.pdf

http://revistas.ucm.es/index.php/CLAC

http://dx.doi.org/10.5209/CLAC.52768

(C) 2016 Zhi Chen 陈芷

Círculo de Lingüística Aplicada a la Comunicación (clac)

Universidad Complutense de Madrid. ISSN 1576-4737. http://www.ucm.es/info/circulo 
Chen Qiongzan (陈琼兟), Fan Jiyan (范继淹) y Zhu Dexi (朱德熙). Un artículo de este último Sobre “的 (De)” ha provocado una amplia reacción y una profunda influencia en las investigaciones posteriores. A pesar de todo y hasta hoy en día, el uso de esta palabra sigue siendo un escollo tanto para los profesores de chino como para sus alumnos. Las ambigüedades que puede causar y la diferencia semántica y pragmática de su uso y desuso han sido un rompecabezas no sólo para los extranjeros, sino también para los nativos. En este artículo, intentaremos delimitar sus usos y analizar sus valores semánticos y pragmáticos.

Palabras clave: Clítico, 的 de, valor gramatical, enseñanza de la lengua china

\section{Abstract}

Clitics play an essential role in the syntactic structure of the Chinese language, owing to the language's intrinsic characteristics. Without clitics, sentences cannot be built, because they - among other things - carry important grammatical content. Indeed, each Chinese clitic has a special grammatical function, and are difficult to replace without changing the original meaning of the sentences.

The word "的” occurs with highest frequency among all Chinese clitics. This, like many other so-called "empty words", serves various Chinese grammatical functions, and thus constitutes a very interesting topic of Chinese grammatical research. Since the 1920s, generations of scholars have devoted themselves to this study, including among others Li Jinxi (黎锦熙), Gao Mingkai (高名凯), Chen Qiongzan (陈琼瓒), Fan Jiyan (范继淹) and Zhu Dexi (朱德熙). One of Zhu’s articles on “的(de)” has provoked widespread scholarly discussion, and has had a profound influence. But even today, the word's use remains a stumbling block for both teachers and students of Chinese. The ambiguities that can potentially occur, as well as the semantic and pragmatic differences of its use and disuse, have puzzled not only foreigners, but also many natives. In this paper, we will attempt to define the appropriate uses for the word, and analyze the word's semantic and pragmatic values.

Key words: Clitic, 的 de, grammatical value, Chinese language teaching 
Índice

1. Introducción 25

2. Usos sintácticos 26

2.1. Marcador genitivo 26

2.2. Marcador de cuasi-modificación 28

2.3. Indicador de sustantivación 32

3. Presencia y ausencia del clítico DE 34

3.1. Cambios semánticos 34

3.2. Cambios sintácticos 36

3.3. Cambios pragmáticos (Función enfática) 37

4. La ambigüedad de la estructura $X D E Y 38$

4.1. La variedad de la construcción genitiva 38

4.2. La distinta segmentación del sintagma 41

4.3. La colocación del clítico “ $D E ” 44$

5. Conclusiones 47

Referencias bibliográficas 47

1. Introducción

En el chino actual, la palabra “的(de)" se presenta con muy alta frecuencia. Según un experimento hecho el día 22 de julio de 2015 a las 18.28 horas (hora de España), en el buscador Google salen 2,180,000,000 resultados relacionados con “的(de)” mientras que en Baidu, buscador número uno de China, salen a su vez unos 100,000,000 resultados, que es el número máximo de cualquier búsqueda. Esta palabra, como muchas otras "palabras vacías", desempeña diversas funciones gramaticales en chino y así constituye un punto de investigación muy interesante en la gramática china. Desde los años 20 del siglo pasado, generaciones de generaciones de eruditos se han dedicado a su estudio, entre otros, figuran Li Jinxi (黎锦熙), Gao Mingkai（高名凯）, Chen 
Qiongzan (陈琼瓒), Fan Jiyan（范继淹）, Zhu Dexi（朱德熙）. Un artículo del último Sobre “的(De)” ha provocado una amplia reacción y profunda influencia en las siguientes investigaciones. A pesar de todo, hasta hoy en día, el uso de esta palabra sigue siendo un escollo tanto para los profesores de chino como para los alumnos. Las ambigüedades que puede causar y la diferencia semántica y pragmática de su uso y desuso, han sido un rompecabezas no sólo para los extranjeros, sino también para los nativos. En el presente artículo, intentaremos delimitar sus usos y analizar sus valores semánticos y pragmáticos. La referencia principal la tomamos de $\mathrm{Xu}$ Yangchun (徐阳春), A study on Form Word “De” and its Related Matters publicado en 2006. Es un libro que ha hecho una evaluación bastante sistemática de todos los estudios realizados hasta ese momento y ha dado una explicación bastante clara y rígida. También incorporamos atribuciones de Hu Yüshu (胡裕树, 1993) y Zhang Bin (张斌, 2004), ambos libros se usan como Manuales de Chino en los Centros Docentes de China.

\section{Usos sintácticos}

\subsection{Marcador genitivo}

El papel primordial que juega “的(de)” en la sintaxis china es el del marcador genitivo. La estructura interna es $X$ 的 $Y$. X es el determinador adjetival de Y, y “的(de)” consiste en clítico y en adelante se denomina “ $D E$ ”. En cuanto a la categoría gramatical de X, puede ser sustantivo, adjetivo, pronombre, verbo e incluso frase. Mientras tanto, $\mathrm{Y}$ puede ser sustantivo o verbo. Veamos los siguientes ejemplos:

1. a) 四季的衣服

sì jì de ȳi fú cuatro estación clítico estructural ropa 'ropa de cuatro estaciones'

b) 激烈的讨论

jī liè de tăo lùn acalorado clítico $\mathrm{EST}_{\mathrm{S}}$ discutir/discusión 'discusión acalorada' 
2. a) 我的书

wǒ de shū

yo clítico ${ }_{\mathrm{EST}}$ libro

'mi libro'

b) 毕加索的画

bì jiā suǒ de huà

Picasso clítico EST pintura

'pintura de Picasso'

3. a) 我们住的那胡司儿

wǒ men zhù de nà hú tòng er ${ }^{1}$

nosotros vivir clítico $\mathrm{EST}_{\mathrm{T}}$ aquel hutong

'Hutong ${ }^{2}$ donde vivimos'

b) 刚做的水果沙律

gāng zuò de shuǐ guǒ shā lǜ

apenas hacer clítico ${ }_{E S T}$ fruta ensalada

'ensalada de fruta recién hecha'

Se puede observar que los dos ejemplos del primer grupo indican una relación descriptiva, en que $\mathrm{X}$ describe al $\mathrm{Y}$. Los ejemplos del segundo grupo ponen en manifiesto una relación de pertenencia o posesión, en que $Y$ pertenece a $X$. Sin embargo, como Picasso es un pintor muy famoso, el 2.b) presenta una ambigüedad semántica muy interesante y representativa, la cual vamos a analizar más en adelante. Los sintagmas del tercer grupo cuentan con un rasgo común: el $\mathrm{X}$ es una frase, que actúa en conjunto para modificar $Y$.

\footnotetext{
1 “er" se considera como sufijo sustantivo. Carece de sentido semántico y es un rasgo fonético muy típico del norte de China.

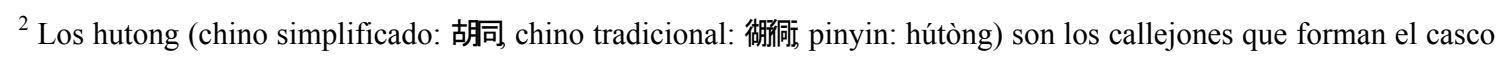
antiguo de la ciudad de Pekín (China). Muchas de estas callejuelas fueron construídas durante las dinastías Yuan, Ming y Qing.
} 
2.2. Marcador de cuasi-modificación

A pesar de que la estructura interna en esta función sigue siendo $X D E Y$, aquí $\mathrm{X}$ no se puede considerar como el mero modificador de Y que tiene un empleo descriptivo y/o delimitativo. Antes de empezar el estudio, primero veamos los siguientes ejemplos:

4. a) 开你的玩笑

kāi nǐ de wán xiào

gastar tú clítico ${ }_{\mathrm{EST}}$ broma

'gastar broma a tí'

b) 帮我的忙

bāng wǒ de máng

prestar yo clítico ${ }_{\mathrm{EST}}$ ayuda

'prestar ayuda a mí'

5. a) 我的东

wǒ de dōng

yo clítico ${ }_{\mathrm{EST}}$ anfitrión

'me hago el anfitrión'

b) 你的原告

nǐ de yuán gào

tú clítico $\mathrm{EST}_{\mathrm{Semandante}}$

'tú eres demandante'

El grupo 4 y 5 muestran un uso muy especial de " $D E$ ". Muchos estudiosos han hecho análisis estructural desde diversos puntos de vista (cf. Zhu Dexi, 朱德熙: 1982; Huang Guoying, 黄国裕: 1982; Zhang Bojiang \& Fang Mei, 张伯江\&方梅: 1996 entre otros). La relación modificadora recibe denominaciones como cuasi-modificación (Zhu), pseudo-modificación (Huang) o pertenecencia en sentido amplio (Zhang\&Fang). En nuestra opinión, estos tres términos, a pesar de la diferencia en la expresión superficial, tienen en común un concepto subyacente, el cual registra una estructura modificadora muy distinta de los tres grupos arriba mencionados.

Veamos el ejemplo 4.a): 
La frase “你的(nǐ de)” no expresa en este ejemplo una relación de posesión o pertenencia, porque no podemos entender “你的玩笑(nǐ de wán xiào)” en este caso como tu broma o broma formulada por tí. Si imaginamos el proceso de formación de este sintagma, primero se estructura una frase de verbo-objeto “开玩笑” (kāi wán xiào, gastar broma), luego se inserta “你的(nǐ de)” entre el verbo “开(kāi)” y el objeto directo “玩笑(wán xiào)”, y así este “你的(nǐ de)” desempeña la función de objeto indirecto en vez de simplemente modificar el sustantivo pospuesto.

Sin embargo, cuando “开你的玩笑(kāi nǐ de wán xiào)” significa “gastarte bromas a

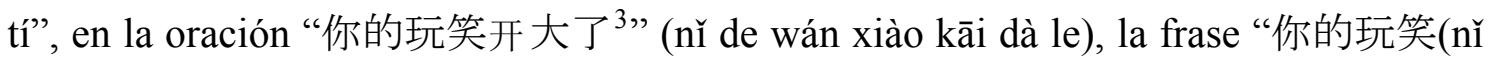
de wán xiào)" expresa una relación modificadora auténtica puesto que “你的(nǐ de)” no es una estructura insertada así que puede restringir directamente el siguiente sustantivo.

Lo mismo pasa con 4.b):

“我的忙(wǒ de máng)” en este caso no significa “mi ayuda”. Porque “我的(wǒ de)” es una estructura insertada en la frase verbo-objeto “帮忙(bāng máng)”. El clítico “DE” en este caso indica que el pronombre antepuesto es el objeto indirecto del verbo. De este modo, “帮我的忙(bāng wǒ de máng)” significa en español “prestarme ayuda a mí”. Pero en la oración “我的忙帮错了" (wǒ de máng bāng cuò le), la frase “我的忙(wǒ de máng)" expresa una relación modificadora auténtica ya que “我的(wǒ de)" no es una estructura insertada. Veamos más ejemplos:

4. c) 别生我的气

bié shēng wǒ de qì

no producir yo clítico ${ }_{\mathrm{EST}}$ ira

'No te enfades conmigo'

d) 泼他的冷水

pō tā de lěng shuǐ

\footnotetext{
${ }^{3}$ Significa "Tu broma ha sido exagerada".

${ }^{4}$ Significa "Mi ayuda ha sido equívoca".
} 
echar él clítico ${ }_{\mathrm{EST}}$ frío agua

'echarle agua fría'

En el ejemplo 4.c), el clítico indica que su host es el objeto del acto. En tanto, el clítico en el ejemplo 4.d) expresa que "él" es el objeto indirecto de "echar".

Veamos ahora los ejemplos del grupo 5:

Aparentemente la estructura es idéntica a la de $X D E Y$. No obstante, $\mathrm{X}$ en este caso no es un simple modificador de Y (como se muestra en los ejemplos del grupo 1-3). Estos dos ejemplos, más bien, se pueden traducir como oraciones de sujeto y predicado. La primera oración “我的东(wǒ de dōng)”, puede aparecer en una escena frecuentemente presentada en los restaurantes chinos cuando un grupo de amigos terminan de comer, y todos "luchan" por pagar, uno de ellos gritará: “我的东, 我的东 ! (wǒ de dōng, wǒ de dōng!)” (¡Soy anfitrión! ¡soy anfitrión! ) Con esta afirmación, el hablante expresa la firme decisión de querer pagar por todos. En el corpus CCL (Center for Chinese Linguistics), hemos encontrado dicho registro, lo cual ejemplifica el frecuente uso de esta frase. Así mismo en el CCL se consta una oración relacionada con el segundo ejemplo: “你的原告, 你先说! ” (nǐ de yuán gào, nǐ xiān shuō!) Entre “你的(nǐ de)” y “原告(yuán gào)” también se nota una relación de sujeto y predicado. El sentido semántico de los dos ejemplos arriba mencionados se puede inducir como "alguien juega tal papel o asume tal cargo".

¿Por qué una misma estructura superficial $(X D E Y)$ produce distinta relación sintáctica? De acuerdo con Zhang Bin (张斌, 2006: 141), eso se debe a la naturaleza de Y. En caso de que $\mathrm{Y}$ es un sustantivo que expresa ideas como identidad, cargo, estatus social etc., la relación sintáctica entre $\mathrm{X}$ y $\mathrm{Y}$, se puede considerar como sujeto y predicado, $\mathrm{X}$ como sujeto y Y, predicado. Veamos los siguientes ejemplos:

5. c) 他的老师当得好。

tā de lăo shī dāng de hăo

\footnotetext{
${ }^{5}$ Significa “Tú eres demandante, ¡dílo tú primero!"
} 
él clítico ${ }_{\mathrm{EST}}$ profesor asumir clítico ${ }_{\mathrm{EST}}{ }^{6}$ bien

'Él asume bien el cargo de profesor.'

d) 梅兰芳的虞姬演得好。

méi lán fāng de yú jī yăn de hăo

Mei Lanfang ${ }^{7}$ clítico $_{\text {EST }}$ Yuji $^{8}$ representar clítico ${ }_{\text {EST }}$ bien

'Mei Lanfang juega bien el papel de Yuji.'

El ejemplo 5.c) no tiene como sujeto "el profesor de él", el clítico en este caso expresa una parte de él---su cargo de ser profesor. Igual como el 5.d), el papel que juega Mei Lanfang es Yuji. Sin duda, cabe señalar que este tipo de uso requiere un gran apoyo contextual. De hecho, en el habla, raras veces se dicen estas oraciones sin ningún contexto.

Hasta aquí, parece posible sacar la siguiente generalización:

(i) En la estructura $X D E Y$, el clítico “ $D E$ ”, prosódicamente se adjunta al elemento anterior X. Sintácticamente, la primera función descansa en marcar la construcción genitiva, la cual denota valores muy complejos, como propiedad, posesión o pertenencia, el objeto sobre el que recae o que produce la acción transitiva expresada por un nombre, la cualidad o la cantidad de algo o de alguien, el precio, una parte de un todo, la naturaleza de algo, etc.

(ii) Si la construcción genitiva expresa una auténtica relación de modificadormodificado, existe otra posibilidad de una relación de cuasi-modificación, que se plasma en dos situaciones: a) cuando el paradigma se presenta como Verbo+Pronombre+DE+Sustantivo (objeto directo del Verbo), y a la vez, la combinación del pronombre y el clítico " $D E$ ” se puede entender como un elemento incrustado entre el Verbo y el Objeto directo, en este caso, el clítico

\footnotetext{
6 “得” es otro clítico que indica relación verbo-complemento.

${ }^{7}$ Mei Lanfang, personaje legendario de la Ópera de Beijing. Es actor pero suele jugar los papeles femeninos.

${ }^{8}$ Yuji, protagonista en una célebre obra teatral "Ba Wang Bie Ji”. En 1993, se filmó una película con el mismo nombre cuya traducción en inglés es "Fairwell My Concubine". A pesar de que Yuji es concubina del Rey Chu, dicho título causará mal efecto al público. Personalmente cosnidero mejor la traducción "Despedida del Rey Chu a su Mujer".
} 
" $D E$ " sirve de marcador de cuasi-modificación, que expresa el objeto indirecto del verbo. b) cuando $\mathrm{Y}$ consiste en palabras que significan "identidad, cargo o estatus social”, el clítico "DE” connota una relación sujeto-predicado entre X y $\mathrm{Y}$, en cuyo uso es precisa una contextualización.

\subsection{Indicador de sustantivación}

Una estructura sintáctica muy importante en la lengua china es la relativa al " $D E$ ", , que constituye una de las construcciones más importantes, por su frecuencia y función articulatoria del discurso, en la sintaxis del chino moderno ${ }^{10}$. La estructura interna es $X$ $D E$. La categoría gramatical de $\mathrm{X}$ puede ser sustantivo, adjetivo, verbo o frases pertinentes. Representamos la relación con el siguiente diagrama:

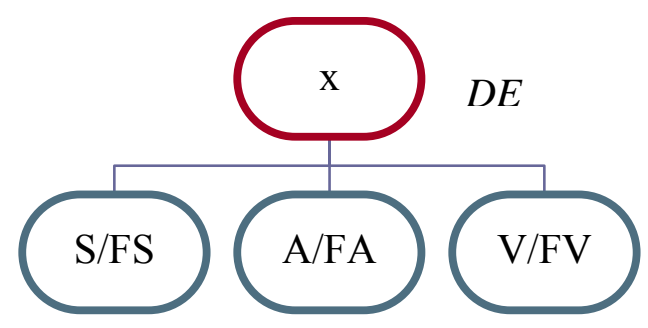

Pongamos unos ejemplos para cada tipo:

S/FS: 木头的 (mù tou de, de madera) ; 我的(wǒ de, lo mío) ; 老张和小李的(lăo zhāng hé xiăo lĩ de, lo de Lao Zhang y Xiao Li)

A/FA: 年轻的 (nián qīng de, lo joven) ; 大的(dà de, lo grande) ; 细一点的(xì yì diăn de, lo de un poco más fino)

V/FV: 说的 (shuō de, el/la/los/las/lo que dice(n)); 教书的(jiāo shū de, el/la/los/las que enseña(n)) ; 参观的(cān guān de, el/la/los/las que visita(n))

Es fácil de observar que en estas frases se da una presencia cero del núcleo. La estructura típica $X D E Y$ que hemos analizado en el pasado pasaje se hace aquí como $X$ $D E$. Frente a este fenómeno, los lingüistas se dividen en dos campos: los de la teoría de

\footnotetext{
${ }^{9}$ Término usado por Laureano Ramírez Bellerín, en Manual de Traducción Chino/Castellano (2004), p. 127

${ }^{10}$ Ibíd, 128
} 
Elipsis y los de la teoría de Sustantivación. Las figuras representativas del primer campo son Li Jinxi (黎锦熙，1924), Wang Li (王力, 1943), Din Shengshu (丁声树，1961), Chao Yuanren (赵元任，1968) etc. Y Zhu Dexi (朱德熙, 1961a, 1966), Lu Jianming (陆俭明，1991)，Hu Yushu (胡裕树，1994), Yuan Yulin (袁毓林，1995a，2002) entre otros, pertenecen al segundo campo. A nuestro juicio, es poco razonable considerar que el núcleo se ha eliminado. Si se tratara de una elisión, el hablante siempre podría recompensar o volver a agregar el núcleo en las oraciones. Sin embargo, existen oraciones en que el núcleo no se puede volver a colocar en la oración. Veamos los siguientes ejemplos sacados de Zhu Dexi (朱德熙，1966):

6. a) 酱油和醋一样打五分钱的( )。

jiàng yóu hé cù yí yàng dă wǔ fên qián de salsa de soja y vinagre igual comprar cinco fen ${ }^{11}$ clítico

'Compra cinco fen de salsa de soja y vinagre respectivamente. '

b) 操纵这台机器的( )不是人而是一架电子计算机。

cāo zòng zhè tái jī qì de bú shì rén ér shì yī jià diàn zǐ jì suàn jī 。 manejar esto clasificador máquina clítico no ser persona sino un clasificador ordenador 'El que maneja esta máquina no es persona sino ordenador.

c) 他笑他的( ), 与你什么相干?

tā xiào tā de, yǔ nǐ shén me xiāng gān?

él reír él clítico, con tú qué relación

'Él se ríe de lo que le dé la gana, ¿a ti qué te importa?'

Se puede percibir que en estos tres ejemplos, es muy difícil incorporar un núcleo en el paréntesis puesto detrás del clítico, o sea, aquí, el clítico “ $D E$ ” cumple la función de presuponer un sujeto u objeto directo tácitos. De acuerdo con Xu Yangchun (徐阳春), en la estructura relativa con " $D E$ " hay que darse cuenta de un núcleo sustantivo cuya presencia es implícita. Con la ayuda del contexto, podemos intuir su existencia, aunque en algunos casos concretos es difícil mostrarlo expresamente. (Xu: 91) Razón por la cual, el

\footnotetext{
${ }^{11}$ Fen: Mínima unidad monetaria en China.
} 
clítico “的(de)" se reconoce como el marcador de sustantivación y la estructura relativa con " $D E$ " es una estructura sustantiva.

\section{Presencia y ausencia del clítico $D E$}

La presencia o ausencia del clítico $D E$ puede provocar cambios semánticos, sintácticos o pragmáticos en la estructura $X D E Y$. Aquí intentamos dar un recorrido breve a estos problemas.

\subsection{Cambios semánticos}

Con los siguientes ejemplos, podemos dar cuenta de la importancia del clítico " $D E$ " en la lengua china, cuyo uso puede alterar gravemente el sentido de la frase.

7.
a) 父亲的母亲
父亲母亲
fù qīn de mǔ qīn
fù qīn mǔ qīn
padre clítico $\mathrm{EST}_{\mathrm{S}}$ madre
padre madre
'madre del padre'
'padre y madre'
b) 狐狸的尾巴
狐狸尾巴
hú lí de wěi bā
hú lí wěi bā
zorro clítico ${ }_{\mathrm{EST}}$ cola
zorro cola
'cola de zorro'
'(asomar) la oreja'
c) 小孩的脾气
小孩脾气
xiăo hái de pí qì
xiăo hái pí qì
niño clítico ${ }_{\mathrm{EST}}$ temperamento
niño temperamento
'temperamento del niño'
'infantilismo'
d) 北京的饭店
北京饭店
běi jīng de fàn diàn
běi jīng fàn diàn
Beijing clítico ${ }_{\mathrm{EST}}$ hotel
Beijing hotel
'hoteles en Beijing'
'el Hotel de Beijing'
e) 我们的老师
我们老师
wǒ men de lăo shī
wǒ men lăo shī
nosotros clítico ${ }_{\mathrm{EST}}$ profesor(es)
nosotros profesores
'nuestro(s) profesor(es)'
'nosotros, los profesores' 
Los ejemplos nos muestran la función que desempeña el clítico " $D E$ " como marcador genitivo. En todas las frases su presencia indica relación de propiedad o posesión. Sin embargo, cuando la estructura $X D E Y$ se convierte en $X Y$, el sentido cambiaría bajo cierto contexto. En 7.a), “父亲母亲(fù qīn mǔ qīn)” con la privación del clítico, se pierde la relación modificador-modificado y se forma una relación coordinada. Respecto al 7.b), “狐狸尾巴(hú lí wěi bā)” ya no se refiere a una parte del cuerpo del zorro, sino constituye una frase hecha que equivale a "(asomar) la oreja" en español. El cambio es idéntico en el 7.c). “小孩脾气(xiăo hái pí qì)” también se logra una frase hecha en chino, en vez de atañer al carácter del niño. Con la pérdida del clítico " $D E$ ", las frases en 7.b) y c) tienen una estructura exocéntrica, cuyo sentido se entiende globalmente como un bloque. En cuanto a “北京饭店(běi jīng fàn diàn)”, ya se refiere específicamente a ese hotel de Beijing y no a todos. El ejemplo 7.e) pone de manifiesto el cambio de una relación modificador-modificado a una apositiva. En algunos casos concretos, “我们老师(wǒ men lăo shī)” se puede entender como “nosotros, los profesores". Veamos el siguiente enunciado:

7. f)这件事虽小，但给我们老师一个启发 : 孩子们是可爱的、善良的, 关键是大人如何引导。

'A pesar de que es un asunto trivial, nos ha dado a nosotros, los profesores, una inspiración: los niños son simpáticos y bondadosos, son los adultos que les tienen que guiar'.

El mismo cambio se da entre “你们的医生” (nǐ men de ȳ̄ shēng, vuestro(s) médico(s)) y “你们医生”(nǐ men yī shēng, vosotros, los médicos); “我们的文艺工作者”(wǒ men de wén yì gōng zuò zhě, nuestro(s) trabajador(es) literario(s) y artístico(s)) y “我们文艺工作者”(wǒ men wén yì gōng zuò zhě, nosotros, los trabajadores literarios y artísticos) etc. Observamos que cuando $\mathrm{X}$ se representa por pronombres personales en plural, así como $\mathrm{Y}$ se trata de cierta profesión o cargo, la estructura $X Y$ se puede considerar como una construcción apositiva cuando el contexto es apropiado. 


\subsection{Cambios sintácticos}

De hecho, los ejemplos 7.a) y 7.d) arriba mencionados ya tratan de un cambio sintáctico de los elementos dentro de la frase, pero como la naturaleza en sí sigue siendo sustantiva, los hemos agrupado en el pasado pasaje. Aquí concentramos unos ejemplos que manifiestan alteración total de la estructura sintáctica, aunque a veces el campo semántico no está severamente afectado. Veamos los siguientes ejemplos:

8.
a) 研究问题
研究的问题
yán jiū wèn tí
yán jiū de wèn tí
estudiar problema
estudiar clítico ${ }_{\mathrm{EST}}$ problema
'estudiar problema'
'el problema que se estudia'
b) 读书
读的书
dú shū
dú de shū
leer libro
leer clítico EST $_{\text {libro }}$
'leer libro'
'libro que se lee'
c) 激烈讨论
激烈的讨论
jī liè tăo lùn
jī liè de tăo lùn
acalorado discutir
acalorado clítico ${ }_{\mathrm{EST}}$ discutir
'discutir acaloradamente'
'discusión acalorada'
d) 认真学习
认真的学习
rèn zhēn xué xí
rèn zhēn de xué xí
diligente estudiar
diligente clítico ${ }_{\mathrm{EST}}$ estudiar
'estudiar diligentemente'
'estudio diligente'
e) 开车
开的车
kāi chē
kāi de chē
conducir coche
conducir clítico ${ }_{\mathrm{EST}}$ coche
'conducir coche'
'el coche que se conduce'

Estos ejemplos son ideales para mostrar la función de sustantivación del clítico DE. Las frases en la columna izquierda son de naturaleza verbal; con la presencia del clítico, se transforman en frases sustantivas, figuradas en la columna derecha, compuestas por un 
sustantivo modificado por un verbo o un adjetivo. En los ejemplos 8.a) y 8.b), se nota que si en una estructura Verbo-objeto se inserta el clítico " $D E$ ", la frase adquiere rasgos sustantivos. Lo mismo ocurre con 8.c), d) y e). Una frase verbal, cuyo núcleo es el verbo, se convierte en frase sustantiva, cuyo núcleo es el sustantivo y el verbo o el adjetivo se convierten en modificadores del sustantivo.

\subsection{Cambios pragmáticos (Función enfática)}

La aparición o desaparición del clítico " $D E$ ” no siempre conduce a cambios semánticos o sintácticos, pero siempre tiende a producir cambios pragmáticos. Conforme con $\mathrm{Xu}$ Yangchun (徐阳春, 2006: 37), la función pragmática que tiene “DE” es destacar la eminencia en sentido inverso, ello es, enfatizar los modificadores de los sustantivos dentro de cierta restricción contextual. Veamos los siguientes ejemplos:

9.

a) 哈佛学生

hā fó xué shēng

Harvard estudiante

'estudiante de Harvard'

b) 木头电线杆

mù tou diàn xiàn gān

Madera poste eléctrico

'poste eléctrico de madera'

c) 学习材料

xué xí cái liào

estudiar materia

'materiales de estudio'

d) 正常程序

zhèng cháng chéng xù

normal procedimiento

'procedimiento normal'
哈佛的学生

hā fó de xué shēng

Harvard clítico ${ }_{\mathrm{EST}}$ estudiante

'estudiante de Harvard'

木头的电线杆

mù tou de diàn xiàn gān

madera clítico ${ }_{\mathrm{EST}}$ poste eléctrico

'poste eléctrico de madera'

学习的材料

xué xí de cái liào

estudiar clítico $\mathrm{EST}_{\mathrm{T}}$ materia

'materiales de estudio'

正常的程序

zhèng cháng de chéng xù

normal clítico EST procedimiento

'procedimiento normal'

Estos ejemplos no enseñan ningún cambio semántico, pero en el habla, en las frases con “ $D E$ ” se nota cierto matiz añadido. La función pragmática del clítico " $D E$ ” consiste en 
enfatizar al modificador o distinguir entre diferentes cualidades, por lo tanto, es en sentido inverso, en vista de que la articulación del lenguaje se desarrolla desde izquierda a la derecha. 9.a) muestra una intención del hablante de destacar la importancia de los alumnos ya que son de Harvard y no de otra universidad cualquiera. 9.b) distingue el material del poste eléctrico de otros que no son de madera. 9.c) difiere materia de estudio de las de otras propiedades, de repaso, por ejemplo. 9.d) connota la existencia de "procedimientos anormales". Vamos a ver el comportamiento de las frases 9.b) en oraciones reales sacadas del CCL.

9. e) 不一会，他发现自己已被包围了，他就将身体靠在一根木头电线杆上， 他听到政委向他喊叫 :

'A poco rato, se dio cuenta de que fue cercado, se apoyó contra un poste eléctrico de madera y oyó el grito del comisario político: '

f) 我想起了石板铺成的大街, 一条比胡同还要窄的大街, 两旁是木头的 电线杆, 里面发出瑏瑏的声响。

'Recordé una calle pavimentada con losas, más estrecha que un callejón, por los dos lados se elevaban postes eléctricos de madera que por dentro zumbaban. '

En 9.e) no hace falta destacar la materia del poste eléctrico porque simplemente el protagonista necesitaba apoyarse contra algo, un poste, un palo, o lo que sea. No obstante, en 9.f) hay que poner de relieve la materia porque si fuese de otra substancia, de cemento o plástico, no emitiría ruidos de zumbido.

\section{La ambigüedad de la estructura $X D E Y$}

Entre $X D E Y$ y $X Y$ existen cambios semánticos, sintácticos, así como pragmáticos. Dentro de la misma estructura $X D E Y$, debido a varias razones, se producen diversas ambigüedades que podrían resultar en malentendidos. Eso se debe a: i) la variedad de la construcción genitiva; ii) la distinta segmentación del sintagma; iii) la colocación del clítico "DE".

\subsection{La variedad de la construcción genitiva}

Ya en 1942, Lü Shuxiang (吕叔湘) declaró las dos relaciones semánticas que puede expresar la construcción genitiva: la de posesión y la de propiedad. Huang Guoying 
(黄国营，1982), Kong Lingda(孔令达，1994), Wen Zhenhui (文贞惠, 1999) y Liu Yonggeng (刘永耕, 1999) han seguido esta línea de investigación y han ampliado y profundizado el tema. Huang ha desarrollado ocho relaciones y Kong ha conseguido catorce. Aún así, los títulos de posesión y de propiedad siguen considerados como los dos prototipos. Es todavía válido el método de distinción formulado por Lü: Si la estructura $X D E Y$ puede convertirse en $X$ 有 $Y$ (X tener $Y$ ), la relación es posesiva. En caso contrario, la relación es de propiedad (Xu Yangchun, 2006: 118). Vamos a ver el ejemplo 2.b) en el pasaje 2.1. con motivo de ensayar este modelo teórico y así intentar dar una explicación elocuente y lógica.

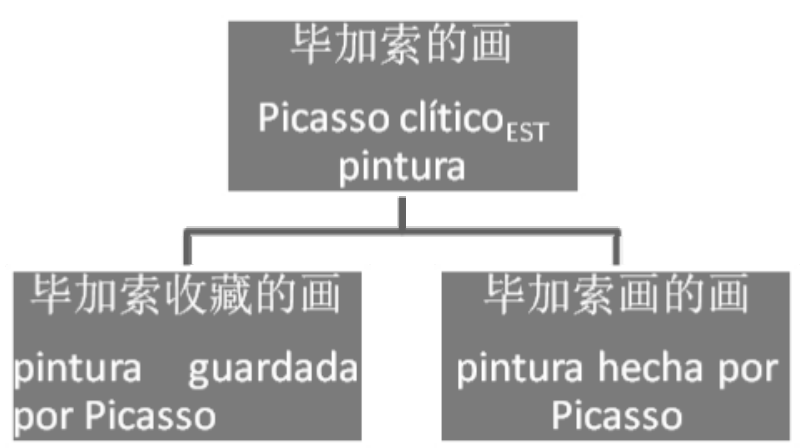

La construcción genitiva marcada por el clítico " $D E$ ” implica dos significados: o bien Picasso tiene la pintura o bien Picasso la pintó. En la primera suposición, la relación entre X y Y (Picasso y la pintura) es posesiva (Picasso tiene la pintura) mientras que en la segunda, la relación es de propiedad, diferenciando esta pintura hecha por Picasso de las de otros pintores, por ejemplo de Van Gogh. Veamos otros ejemplos:

Ejemplo 10.a)

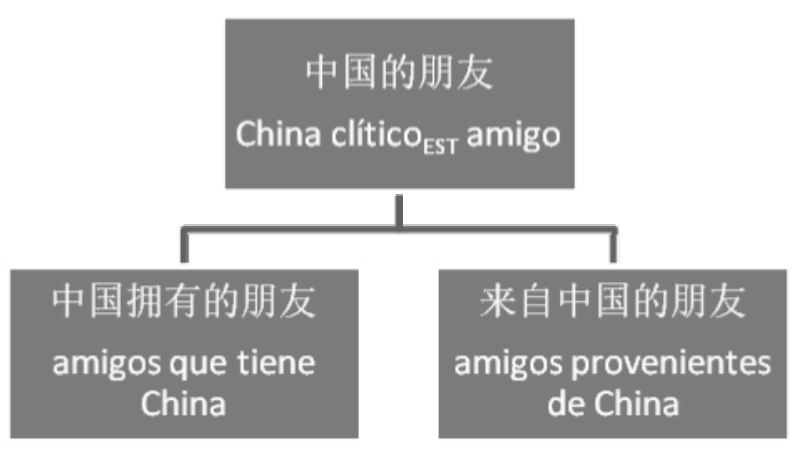


Ejemplo 10.b)

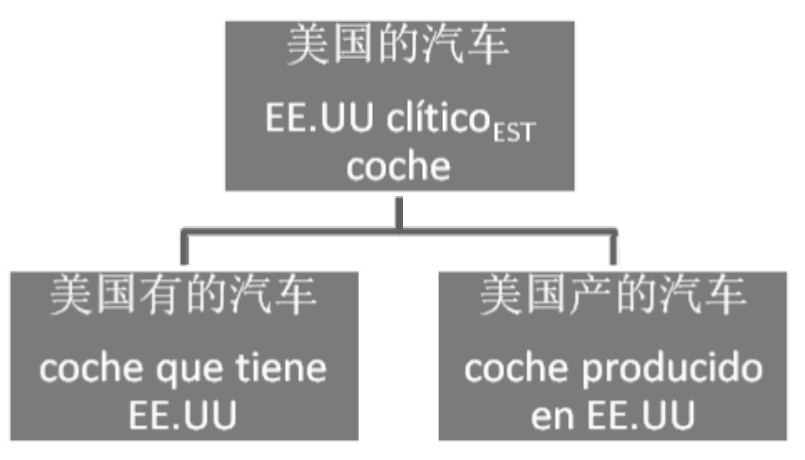

En 10.a), si la relación entre X (中国, China) y Y (朋友, amigo) se mide como posesiva, entonces la frase se refiere a los amigos de China, países o personas, que no tienen la nacionalidad de China. Si la relación es de propiedad, quiere decir que los mismos amigos son chinos. La misma explicación se puede dar con el ejemplo 10.b). Aquí vamos a poner la frase en dos oraciones para que se vea con más claridad.

10. c)美国的汽车是一种文化。

'Los coches en América constituyen una cultura'.

d) 他有一辆美国的汽车。

'Él tiene un coche americano'.

En 10.c) “美国(EE.UU.)” y “汽车(coche)” presentan una relación posesiva en sentido amplio. Es difícil decir que EE.UU., como país, puede tener algún coche, pero en sentido amplio, los coches que pertenecen a EE. UU. representan una cultura. En 10.d), está claro que el coche que tiene él es de USA, no de Japón ni Alemania.

Desde el punto de vista de la gramática generativa, el velo misterioso de este tipo de ambigüedad se puede correr con la especificación del verbo subyacente, recóndito en la estructura X DE Y. A través de los tres ejemplos arriba mencionados, se puede observar que siempre hay un verbo implícito existente en la estructura subyacente a pesar de la igualdad en la estructura superficial. Una vez puesto en una oración (en un contexto), este verbo escondido se vuelve emergente. Con eso, se puede precisar uno u otro de los posibles sentidos. 


\subsection{La distinta segmentación del sintagma}

Existe otra ambigüedad cuyo factor causal no consiste en el verbo oculto, sino en la segmentación del sintagma. Veamos los siguientes ejemplos:

\section{1. a) 对小王的意见}

duì xiăo wáng de yì jiàn

hacia Xiaowang clítico ${ }_{\mathrm{EST}}$ queja

'sobre las quejas a Xiaowang' (A)

'sobre las quejas de Xiaowang' (B)

b) 消灭敌人的主力部队

xiāo miè dí rén de zhǔ lì bù duì

aniquilar enemigo clítico ${ }_{\mathrm{EST}}$ fuerza principal

'la fuerza principal que aniquila al enemigo' (A)

'aniquilar la fuerza principal del enemigo' (B)

c) 反对南非种族主义者的宣传

făn duì nán fēi zhǒng zú zhŭ yì zhě de xuān chuán

oponerse Sudáfrica racista clítico ${ }_{\mathrm{EST}}$ propaganda

'propaganda que se opone a los racistas de Sudáfrica' (A)

'oponerse a la propaganda de los racistas de Sudáfrica' (B)

Estos tres ejemplos pueden diferir totalmente en el significado conforme a los distintos modos de segmentación, cuya causa radica en la variación de la combinación de Preposición/Verbo con el objeto. Si aplicamos el análisis estructural, podemos ver con más claridad la composición lingüística de cada uno de ellos.

\section{1.a) 对小王的意见}

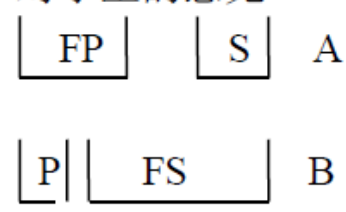

En este ejemplo, el clítico " $D E$ ” es el marcador genitivo. Si no existiera la preposición “对(duì, hacia)”, la frase sería muy fácil de entender: "las opiniones (quejas) de Xiaowang”. Ahora, con la presencia de “对(hacia)”, el sentido de la frase varía según la relación entre la preposición “对(dui)” y el objeto “小王(xiăo wáng)”. Siguiendo al 
modelo A, la frase quiere decir que las quejas se dirigen hacia Xiaowang ya que la parte modificadora de "las quejas" consiste en "hacia Xiaowang". Refiriéndose al modelo B, el objeto de “对(dui)” recae en toda la frase sustantiva “las quejas formuladas por Xiaowang", en este caso, la frase significa "respeto a las quejas de Xiaowang".

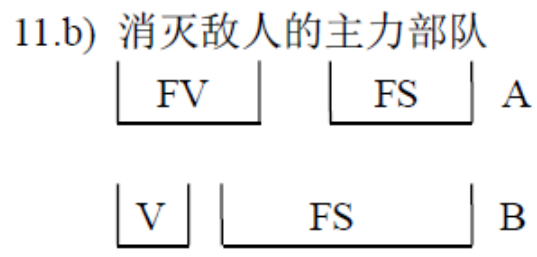

Aquí con la segmentación del modelo A, la frase tiene naturaleza sustantiva, el núcleo es “主力部队”(zhǔ lì bù duì, la fuerza principal), y la estructura Verbo-objeto “消灭敌人” (xiāo miè dí rén, aniquilar el enemigo) lo modifica. En cambio, con el modelo B, la frase tiene una estructura de Verbo-objeto, el verbo es “消灭” (aniquilar), el objeto es “敌人的主力部队” (la fuerza principal del enemigo), en que el núcleo es “主力部队”(la fuerza principal) y “敌人”(el enemigo) lo modifica.

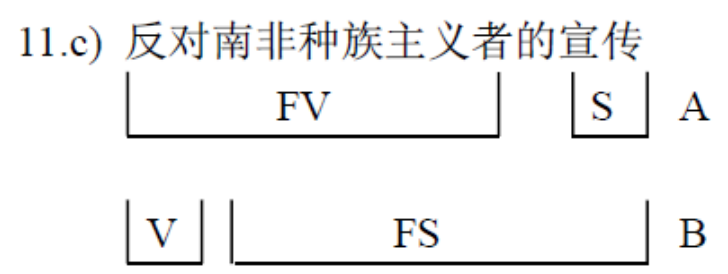

Igual como la manera fragmentaria aplicada en 11.a) y b), aquí primero dividimos como un bloque entero toda la parte anterior que el clítico " $D E$ ", de este modo, la frase tiene naturaleza sustantiva puesto que el núcleo es el nombre “宣传” (xuān chuán, propaganda), la frase verbal “反对南非种族主义者(fãn duì nán fēi zhǒng zú zhǔ yì zhě, los que están en contra del racismo sudafricano)" ejerce la función de su modificador. Así contestamos a la pregunta “¿Qué tipo de propaganda?” Pues, la propaganda que se opone a los racistas en Sudáfrica. Bajo el marco del modelo B, el verbo “反对(făn dui)” rige toda la frase sustantiva “南非种族主义者的宣传(nán fēi zhǒng zú zhŭ yì zhě de xuān chuán)”, en que “宣传(xuān chuán)” es el núcleo y “南非种族主义者(nán fēi zhǒng zú zhǔ yì zhě)” lo modifica. 
En resumidas cuentas, se podría deducir la siguiente fórmula: en una estructura como Preposición/Verbo + Sustantivo $_{1}+$ clítico + Sustantivo $_{2}$, hay dos modelos de segmentación.

\section{Modelo A:}

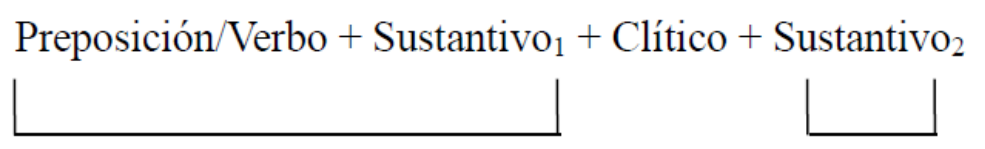

En este caso, el núcleo de toda la frase descansa en Sustantivo2, por lo tanto, la frase tiene naturaleza sustantiva, y contesta la pregunta de “¿Qué tipo de Sustantivo2?”. Volvamos a ver los ejemplos arriba mencionados:

11.a) 对小王的意见

FP $\mathrm{S}$

Contesta la pregunta de “¿Qué tipo de quejas?”

La respuesta sería "quejas hacia Xiaowang."

11.b) 消灭敌人的主力部队

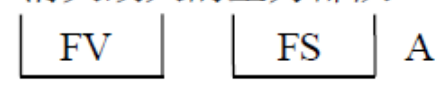

Contesta la pregunta de “¿Qué tipo de fuerza principal?”

La respuesta sería "la fuerza principal que aniquila al enemigo"

11.c) 反对南非种族主义者的宣传

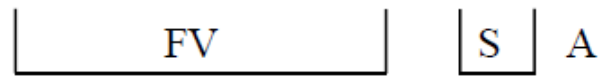

Contesta la pregunta de “¿Qué tipo de propaganda?”

La respuesta sería "la propaganda que se opone a los racistas de Sudáfrica"

\section{Modelo B:}

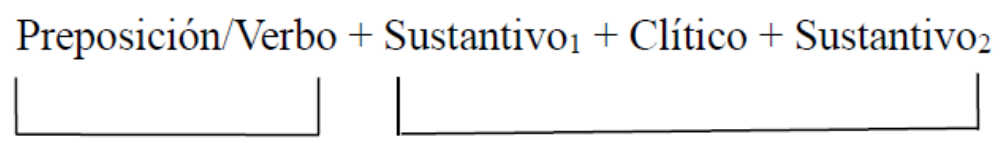

En este modelo, el núcleo de toda la frase es la preposición o el verbo, la estructura sería Preposición-objeto o Verbo-objeto. Y contesta la pregunta de “¿Qué hace?”. También veamos los mismos ejemplos: 
11.a) 对小王的意见

P $\mid$ FS

B

Contesta la pregunta de "¿A qué se refiere?"

La respuesta sería "Se refiere a las quejas hacia Xiaowang"

11.b) 消灭敌人的主力部队

$\mathrm{V} \mid \mathrm{FS} \quad \mathrm{B}$

Contesta la pregunta de "¿Qué aniquila?"

La respuesta sería "aniquilar la fuerza principal del enemigo"

11.c) 反对南非种族主义者的宣传

$\mathrm{V} \mid \mathrm{FS} \quad \mathrm{B}$

Contesta la pregunta de "¿A qué se opone?"

La respuesta sería "oponerse a la propaganda de los racistas de Sudáfrica"

\subsection{La colocación del clítico " $D E "$}

En el apartado anterior, hemos analizado las distintas segmentaciones del sintagma con la presencia del clítico " $D E$ ", de hecho, gracias a su función de marcador genitivo, su colocación diferente en la estructura $X Y$ permite crear nuevas relaciones sintácticas. Veamos los siguientes ejemplos:

12.

Estructura $X Y$

a) 新学生宿舍

b) 回收塑料桶

\section{Colocación A}

新的学生宿舍

xīn de xué shēng sù shè nuevo clítico ${ }_{\mathrm{EST}}$ estudiante

colegio mayor

'nuevo colegio mayor para

los estudiantes'

回收的塑料桶

huí shōu de sù liào tǒng

reciclar clítico ${ }_{\mathrm{EST}}$ plástico

\section{Colocación B}

新学生的宿舍

xīn xué shēng de sù shè

nuevo estudiante

clítico $_{\mathrm{EST}}$ colegio mayor 'colegio mayor para los

nuevos estudiantes'

回收塑料的桶

huí shōu sù liào de tǒng reciclar plástico clítico ${ }_{\mathrm{EST}}$ 


$$
\begin{aligned}
& \text { cubo cubo } \\
& \text { 'cubo plástico reciclado' 'cubo para reciclar } \\
& \text { plástico' } \\
& \text { c) 意大利时何追随者 意大利的时咼追随者意大利时份的追随者 } \\
& \text { yì dà lì de shí shàng zhū } \quad \text { yì dà lìshí shàng de zhū } \\
& \text { suí zhě suí zhě } \\
& \text { Italia clítico }{ }_{\mathrm{EST}} \text { moda Italia moda clítico } \\
& \text { perseguidor perseguidor } \\
& \text { 'perseguidores italianos de 'perseguidores de la } \\
& \text { moda' moda italiana' }
\end{aligned}
$$

Sin contar con el clítico " $D E$ ", cada uno de estos tres ejemplos tienen un sustantivo como núcleo y dos modificadores. Dependiendo de la colocación del clítico, se forman distintas relaciones modificador-modificado.

El análisis estructural de estos ejemplos consta en lo siguiente:

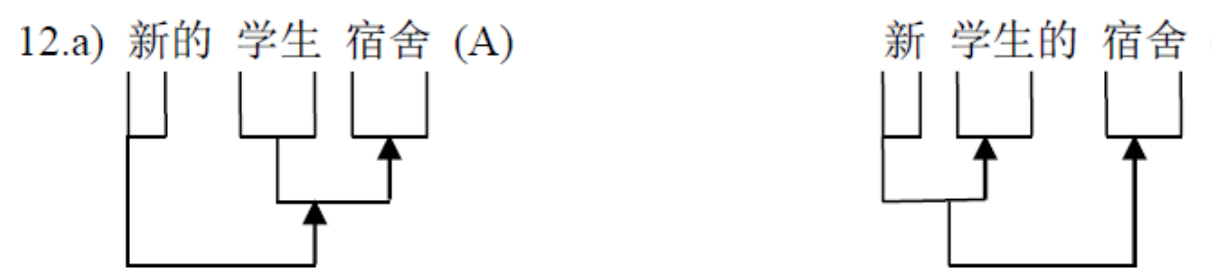

En el modelo A, “学生” (estudiante) y “宿舍” (colegio mayor) constituyen una frase sustantiva y el adjetivo "nuevo" modifica al bloque entero mientras que en el modelo B, “新学生(nuevo estudiante)” es una frase sustantiva que modifica al núcleo “宿舍” (colegio mayor). La diferencia se debe a la colocación del clítico " $D E$ ", que separa de forma distinta los elementos lingüísticos y así da distintos resultados sintácticos.

12.b) 回收的 塑料 桶 (A)
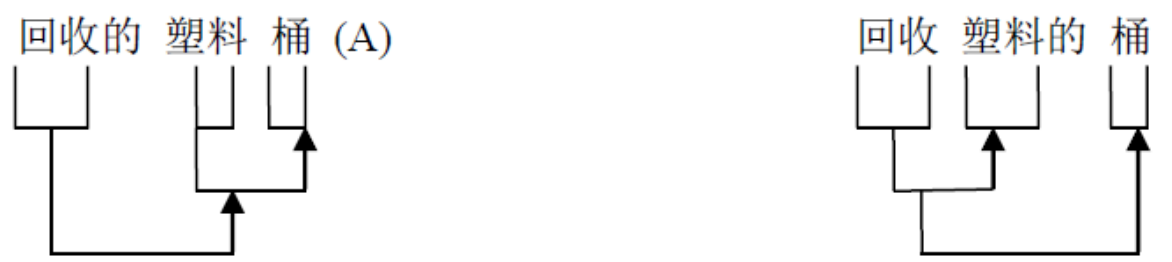

Igual como en el anterior ejemplo, el clítico "DE" también segmenta las frases en distintas unidades. En el modelo A, el modificador2 se junta con el sustantivo y se hace una unidad y ejerce la función del núcleo de toda la frase. El modificador1 lo restringe. 
En el modelo B, en cambio, los dos modificadores forman una unidad y modifican conjuntamente al sustantivo.
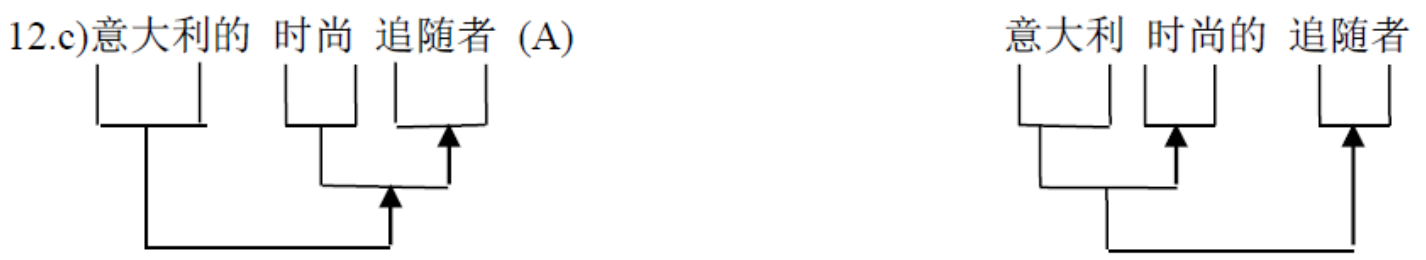

En el modelo A, atribuido a la separación del clítico, “时占追随者” (perseguidores de moda) es un conjunto, "Italia" lo restringe. En el modelo B, como el clítico se coloca después de “时合” (moda), ésta se ve forzada de juntarse con “Italia” y los dos como un modificador entero restringen a “追随者”(perseguidor).

Así se podría sacar la siguiente generalización:

\section{Modelo A}

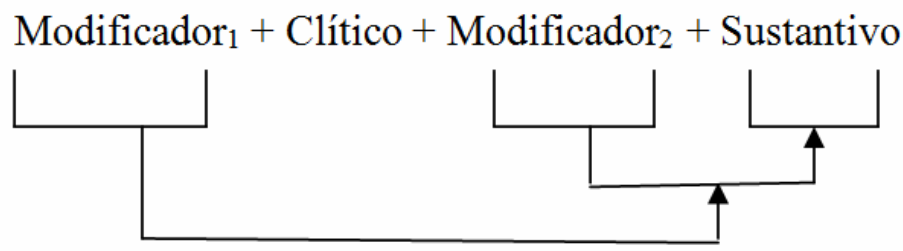

Modelo B

Modificador $_{1}+$ Modificador $_{2}+$ Clítico + Sustantivo

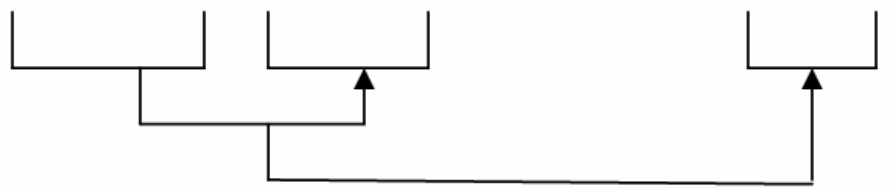

Estos dos modelos, gracias a la existencia del sustantivo, se consideran como frases

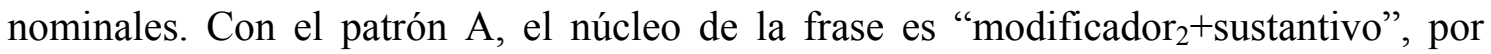

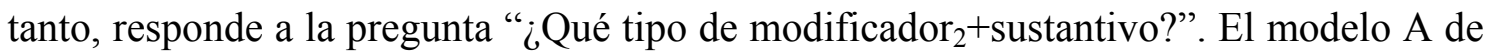
los ejemplos arriba mencionados contesta respectivamente: “¿Qué tipo de colegio mayor para estudiantes?” (Nuevo); “¿Qué tipo de cubo plástico?’(Reciclado) y “¿Qué tipo de perseguidores de moda?"(Italianos). Con el patrón B, el núcleo de toda la frase reside en el elemento siguiente al clítico: el sustantivo. Así responde a la pregunta “¿Qué tipo de sustantivo?”. El modelo B de los ejemplos contesta respectivamente: 
“¿Qué tipo de colegio mayor” (para los nuevos estudiantes); “Qué tipo de cubo?” (cubo para reciclar plástico); “Qué tipo de perseguidores?” (de la moda italiana).

\section{Conclusiones}

Con los ejemplos analizados hemos intentado hacer un análisis sistemático del clítico "DE" solucionando los problemas que se presentan. Cabe señalar que las ambigüedades relacionadas con el uso de esta palabra, se podrían solucionar o en el contexto o en la prosodia (cf. $\mathrm{Hu}$ Yüshu: 350-351). Por ejemplo, cuando pronunciamos “消灭敌人的主力部队(xiāo miè dí rén de zhǔ lì bù duì)”, si añadimos una pausa notable después del verbo “消灭(xiāo miè)”, la frase adquirirá una naturaleza Verboobjeto. En cambio, si la pausa aparece después del clítico " $D E$ ", es obvio que la frase es sustantiva. Así que hay lingüistas que afirman que la estructura $X D E Y$ sólo es ambigua en la lengua y no en el habla. (cf. Hu Yüshu, 胡裕树: 1993; Wu Jingcun y Hou Xuechao, 吴竞存、侯学超: 1982).

\section{Referencias bibliográficas}

Cao, G. 曹广顺. (1995). 近代汉语助词 [Partículas del chino moderno]. 语文出版社 [Editorial Yuwen].

Che，J. 车竟. (1994).“试论“ $\mathrm{N}+\mathrm{V}$ ’式定心结构”[Aproximación al sintagma N+V]. 汉语学习 [Estudio sobre la lengua china], (1).

Ding, S. et.al. 丁声树等. (1961). 现代汉语语法讲话 [Discurso sobre la gramática del chino moderno]. 北京[Beijing]: 商务印书馆[Editorial Shangwu Yinshuguan].

Fan, J. 范继淹. (1979). “的” 字短语代替名词的语义规则[Reglas semánticas de la sustitución de sustantivos por DE]. 中国语文通讯 [El chino], (3), 1-7.

Zhang, B., Fan K. \& Zhang, Y. 张斌, 范开泰, \& 张亚军. (2000). 现代汉语语法分析 (Vol. 225) [Análisis de la gramática del chino moderno]. 上海[Shanghai]: 华东师范大学出版社[Editorial Huadong Shifan Daxue]. 
Fan, X (ed.) 范晓 (主编). (1998). 汉语的句子类型 [Tipología de las oraciones en chino]. 太原[Taiyuan]: 书海出版社[Editorial Shuhai].

Fang, Y. 房玉清. (1992). 实用现代汉语语法 [Gramática práctica del chino moderno]. 北京[Beijing]: 北京语言学院出版社[Editorial Beijing Yuyan Xueyuan].

Guo， R. 郭锐. (2000).“的”字的作用” [Funciones de DE]. 面临新世纪挑战的现代汉语语法研究（陆俭明主编）[Investigaciones gramaticales del chino moderno en el nuevo siglo]. 山东[Shandong]: 山东教育出版社[Editorial Shandong Jiaoyu].

Hou, X. (ed.) 侯学超 主编. (1998). 现代汉语虚词词典 [Diccionario de las palabras vacías del chino]. 北京[Beijing]: 北京大学出版社[Editorial Beijing Daxue].

Hu, Y. (ed.) 胡裕树 主编. (1993). 现代汉语 (增订本) [Chino moderno] (Versión actualizada). 上海[Shanghai]: 上海教育出版社[Editorial Shanghai Jiaoyu].

Hu, Y., Fan, X. 胡裕树, 范晓. (1994). “动词形容词的“名物化”和“名词化”” ['Nominalización' y 'sustantivación' del verbo y adjetivo]. 中国语文[Lengua china] (2).

Huang, B., Liao, X. (ed.) 黄伯荣, 廖序东 主编. (2005). 现代汉语 (增订版) [Chino moderno] (Versión actualizada). 北京[Beijing]：高等教育出版社[Editorial Gaodeng Jiaoyu].

Ji, X. 季羡林. (1991). 神州文化集成丛书序 [Prólogo a la colección de libros sobre la cultura china]. 北京[Beijing]: 新华出版社[Editorial Xinhua].

Kong, L. 孔令达. (1994). “名 $1+$ 名2”结构中名2省略的语义规则”[Reglas semánticas sobre la omisión del Sustantivo 2 en el sintagma Sustantivo 1 + Sustantivo 2]. 九十年代语法思考 [Reflexiones sobre la gramática en los años noventa]. 北京[Beijing]: 北京语言学院出版社[Editorial Beijing Yuyan Xueyuan].

Li，J. 黎锦熙. (1924). 1998. 新著国语文法 [Nueva gramática de la lengua china]. 北京[Beijing]: 商务印书馆[Editorial Shangwu Yinshu]. 
Lu，J. 陆俭明. (1963). “的”的分合问题及其他”[Cuestiones sobre la separación y la adhesión de DE]. 语言学论丛 [Foro sobre la lingüística], (5).

Lu，J. 陆俭明. (1983).“的”字结构和“所”字结构”[Estructura relativa a DE y SUO]. 现代汉语虚词散论 [Ensayos sobre las palabras vacías del chino]. 北京[Beijing]: 语文出版社[Editorial Yuwen].

Lü，Sh. 吕叔湘. (1942). 1982. 中国文法要略 [Esquema de la gramática del chino]. 北京[Beijing]: 商务印书馆[Editorial Shangwu Yinshuguan].

Lü, Sh. 吕叔湘. (1943). 1999. 汉语语法论文集 [Actas de la gramática del chino]. 北京[Beijing]: 商务印书馆[Editorial Shangwu Yinshuguan].

Lü，Sh. 吕叔湘. (1955). 语法学习 [Estudio sobre la gramática]. 北京[Beijing]: 中国青年出版社[Editorial Zhongguo Qingnian].

Lü，Sh. 吕叔湘. (1979). 汉语语法分析问题 [Análisis de la gramática del chino]. 北京[Beijing]: 商务印书馆[Editorial Shangwu Yinshuguan].

Lü, Sh. 吕叔湘. (1981). “关于“的、地、得, 和“做、作” ’ [Sobre 的DE, 地DE, 得DE y 做ZUO y 作ZUO]. 语文学习 [Estudio del chino], (3).

Lü，Sh. 吕叔湘. (1986). “汉语句法的灵活性”[La flexibilidad de la sintaxis china]. 中国语文[La lengua china], (1).

Ma, Zh., Lu, J. 马真, 陆俭明. (1996).““名词十动词”词语串浅析”[Breve análisis sobre el sintagma de sustantivo + verbo]. 中国语文[La lengua china], (3).

Qian, N. 钱乃荣. (2001). 现代汉语 [El chino moderno]. 南京[Nanjing]: 江苏教育出版社[Editorial Jiangsu Jiaoyu].

Shi, Y., Li， N. 石毓智，李讷. (1998). “汉语发展史上结构助词的兴替 : 论“的”的语法化历程”[Partículas estructurales en la historia del chino: proceso de gramaticalización de DE]. 中国社会科学 [Ciencias sociales de China], (6).

Sun, X. 孙锡信. (1999). 近代汉语语气词 [Partículas modales en el chino moderno]. 北京[Beijing]: 语文出版社[Editorial Yuwen]. 
Xu，Y. 徐阳春. (2006). 虚词“的”及其相关问题咑究 [Investigación sobre DE y las cuestiones relativas]. 北京[Beijing]: 文化艺术出版社 [Editorial Wenhua Yishu].

Wang, L. 王力. (1943). 1985. 中国现代语法 [La gramática sobre el chino moderno]. 北京 [Beijing]: 商务印书馆[Editorial Shangwu Yinshuguan].

Wang, L. 王力. (1957). 1985. 汉语语法纲要 [Esbozo de la gramática de la lengua china]. 王力文集（三） [Obras seleccionadas de Wang Li, III]. 山东[Shandong]: 山东教育出版社[Editorial Shandong Jiaoyu].

Wen, Zh. (Corea) 文贞惠 [韩]. (1998). “表属性范畴的“ $\mathrm{N}_{1}$ （的） $\mathrm{N}_{2}$ '结构的语义分析” [Análisis semántico del sintagma $\mathrm{N}_{1}$ DE $\mathrm{N}_{2}$ ]. 世界汉语教学[Enseñanza del chino en el mundo], (1).

Zhu, D. 朱德熙. (1966). 关于《说“的”》 [Sobre “Hablando de DE”]. 中国语文 [La lengua china], (1).

Recibido: 24 de enero de 2016

Aceptado: 18 de mayo de 2016

Publicado: 30 de mayo de 2016 